Int. Agrophys., 2021, 35, 227-234

\title{
Soil salinity management using a Field Monitoring System (FMS) in tsunami-affected farmlands in Miyagi, Japan**
}

\author{
Ieyasu Tokumoto ${ }^{1 *}$, Katsumi Chiba ${ }^{2}$, and Masaru Mizoguchi ${ }^{3}$ \\ ${ }^{1}$ Faculty of Agriculture, Saga University, Honjo, Saga 840-8502, Japan \\ ${ }^{2}$ School of Project Design, Department of Regional Sciences, Miyagi University, Hatatate, Taihaku-ku, Sendai, Miyagi 982-0215, Japan \\ ${ }^{3}$ Department of Global Agricultural Sciences, University of Tokyo, Yayoi, Bunkyo-ku, Tokyo 113-8657, Japan
}

Received February 9, 2021; accepted September 8, 2021

\begin{abstract}
Since the 2011 Tohoku earthquake in Japan, natural rainfall has helped to reduce the salinity levels in the root zone of agricultural fields. However, leaching resulting from natural rainfall alone was insufficient for crop management in tsunamiaffected regions, where severe subsidence had occurred. In order to understand the desalinization process, a Field Monitoring System was installed with time domain transmission, a sensor network technology used to investigate high soil moisture and high salinity levels in a tsunami-affected field in Miyagi. Using the Field Monitoring System with time domain transmission, volumetric soil water content and bulk soil electrical conductivity was monitored in tsunami-damaged farmland before-and-after the application of two weeks of the flooded leaching method with the addition of a topsoil layer. Pore water electrical conductivity may be estimated based on volumetric soil water content and bulk soil electrical conductivity using the Rhoades model. During the flooded leaching period, in situ bulk soil electrical conductivity dropped above the deeper groundwater but did not decrease near the boundary between the added topsoil and the salt affected cracking subsoil. This indicates that preferential flow may have occurred, and flooded leaching was not enough to reduce the salinity level near the boundary. Pore water electrical conductivity was an excellent indicator of whether the field's salinity level was low enough to maintain moderately salinity sensitive crops such as rice and soybean through Field Monitoring System real time monitoring.

Keyw ords: desalinization, Rhoades model, pore water electrical conductivity, flooded leaching
\end{abstract}

*Corresponding author e-mail: yasu@cc.saga-u.ac.jp **The research was supported by a grant from the Japan Society for the Promotion of Science (Research Project Number: 26511009; 2014-2017).

\section{INTRODUCTION}

The March 11, 2011 M9.0 megathrust earthquake off the East Coast of Japan generated a devastating tsunami that inundated over $1300 \mathrm{~km}$ of the Pacific Coast. It reached approximately $5 \mathrm{~km}$ inland in some areas of Miyagi, Japan (Earthquake and Reconstruction Division of Miyagi Prefecture, 2014). The tsunami caused extensive damage to thirteen thousand hectares of farmland, which included collapsed houses, buildings, and many types of infrastructure (Chiba et al., 2014; Roy et al., 2015). Since the disaster, according to a master plan initiated by the Ministry of Agriculture, Forestry and Fisheries (MAFF) of Japan, various recovery/remedial works have been carried out (MAFF, 2011). A 1:5 soil to water extract electrical conductivity $\left(E C_{1: 5}\right)$ test is recommended in MAFF guidelines to evaluate soil salinity levels. Some studies reported that natural rainfall helped to reduce the salinity levels $\left(E C_{1: 5}<0.6 \mathrm{dS} \mathrm{m}^{-1}\right)$ in the plow layer (up to $20 \mathrm{~cm}$ ) of paddy fields with cracks near the soil surface (Chague-Goff et al.; 2012, JIID, 2013; Terasaki et al., 2015). However, Chiba et al., (2014) reported that leaching effects originating from natural rainfall alone was insufficient for rice growth in tsunami-affected regions, where severe subsidence occurred.

In most cases, downward infiltration could accomplish sufficient salt exclusion through drainage canals in paddy fields (Chiba et al., 2015). However, the $E C_{1: 5}$ method

(C) 2021 Institute of Agrophysics, Polish Academy of Sciences 
would be a time and labour consuming choice with which to conduct a long-term investigation into the desalinization process. Instead, pore water electrical conductivity $\left(E C_{w}\right)$ estimated using volumetric soil water content $(\theta)$ and bulk soil $E C\left(E C_{b}\right)$ are a useful way of monitoring soil salinity conditions. Recently, $\theta$ and $E C_{b}$ measurements have become available through the use of commercial soil moisture sensors such as time domain reflectometry (TDR) (Noborio et al., 2001; Miyamoto et al., 2015) and time domain transmissions (TDT) (Miyamoto et al., 2013; Hirashima et al., 2020). These measurement techniques allow for the attainment of in situ $\theta$ and $E C_{b}$ data simultaneously.

A Field Monitoring System (FMS) developed by Mizoguchi et al., (2012) can be used to facilitate agricultural production recovery on damaged lands through the real time monitoring of $\theta$ and $E C_{b}$. The FMS includes two central systems: field measurements and a monitoring system. The FieldRouter (FR) allows for the collection of in situ data and field photos through Bluetooth, which are then sent to a data server over the Internet. For monitoring high $E C_{b}$ in the soil through FMS, the TDT sensor (Acclima) is more affordable than the TDR sensor because of the SDI-12 protocol, which is a standard for interfacing data recorders with microprocessor based sensors (SDI-12 support group, 2012). Additionally, the TDT sensor is a low cost, high precision method used for $\theta$ estimation, and it also has a lower user ability requirement for TDT waveform analysis (Blonquist Jr. et al., 2005). The advantage of FMS with TDT sensors is to obtain accurate $\theta$ and $E C_{b}$ in the root zone because both values are required to estimate $E C_{w}$ for the evaluation of the desalinization process.

For example, the relationship between $\theta, E C_{b}$ and $E C_{w}$ was described by the Rhoades model (Rhoades et al., 1976):

$$
E C_{b}=E C_{w} \theta T_{\text {coef }}+E C_{s},
$$

where: $T_{\text {coef }}$ is interpreted as the soil specific transmission coefficient to account for changes in tortuosity within the electrical current flow path in response to changes in $\theta$, and $E C_{s}$ is the bulk surface conductivity of soil particles. The soil specific transmission coefficient may be expressed by:

$$
T_{\text {coef }}=a \theta+b,
$$

where: $a$ and $b$ are empirical parameters, depending on soil types. This theoretical model describing the dependence of $E C_{b}$ on $E C_{w}$ and $\theta$ (e.g., Rhoades et al., 1976; Rhoades et al., 1989; Mualem and Friedman, 1991; Malicki and Walczak, 1999 ) is used to estimate $E C_{w}$ for a given combination of the measured $E C_{b}$ and $\theta$ in a particular soil (e.g., Mallants et al., 1996; Risler et al., 1996; Muñoz-Carpena et al., 2005). In other words, the close dependence of $E C_{b}$ on $\theta$ makes it difficult to understand the desalinization process without $E C_{w}$ when $\theta$ changes in natural conditions (Seki et al., 2019). Hence, the analysis of salt leaching in fields using $E C_{w}$ must be significant. Also, $E C_{w}$ is usually proportional to chloride ion $\left(\mathrm{Cl}^{-}\right)$ concentration, which influences crop yield (Abe et al., 2017).

To assist in the process of the recovery of agricultural production, this study aimed to evaluate the impact of flooded leaching and natural rainfall on the desalinization process using FMS with TDT sensors in Higashimatsushima of Miyagi, where severe subsidence occurred. Using the Rhoades model, the relationship between $\theta, E C_{b}$, and $E C_{w}$ was revealed in the laboratory, research efforts were then focused on the decline in in situ $E C_{w}$ following two weeks of application of the flooded leaching method with topsoil addition. Additionally, $\mathrm{Cl}^{-}$concentration profiles were estimated based on the $E C_{w}$ results for different crop management methods.

\section{MATERIALS AND METHODS}

Field measurements of the FMS were conducted at a site of the tsunami-damaged farmlands of Higashimatsushima (38 25'38.6"N 141 $\left.{ }^{\circ} 14^{\prime} 46.4^{\prime \prime E}\right)$ in Miyagi, Japan, in 2014 and 2015 (Fig. 1). In Higashimatsushima, $40 \%$ of the entire tsunami-damaged area of 3600 ha consisted of farmland. In the region, subsidence was $60 \mathrm{~cm}$, and organic rich and muddy sediments dominated the soil type. The groundwater level (GWL) was shallow, and the soil became quickly saturated after rainfall events. In 2013, debris was removed, and a drainage pumping station started operation. Irrigation water was delivered to outlets through underground pipelines and was supplied to the paddy fields. At the end of October 2014, a treatment consisting of spreading $10 \mathrm{~cm}$ of topsoil was carried out to lower the groundwater depth. The average saturated hydraulic conductivity $\left(\mathrm{K}_{\mathrm{s}}\right)$ and dry bulk density $\left(\rho_{b}\right)$ were measured using undisturbed soil core samples taken from a layer between 10 and $45 \mathrm{~cm}$, the results were $1 \mathrm{~cm} \mathrm{~d}^{-1}$ and $1.1 \mathrm{~g} \mathrm{~cm}^{-3}$, respectively.

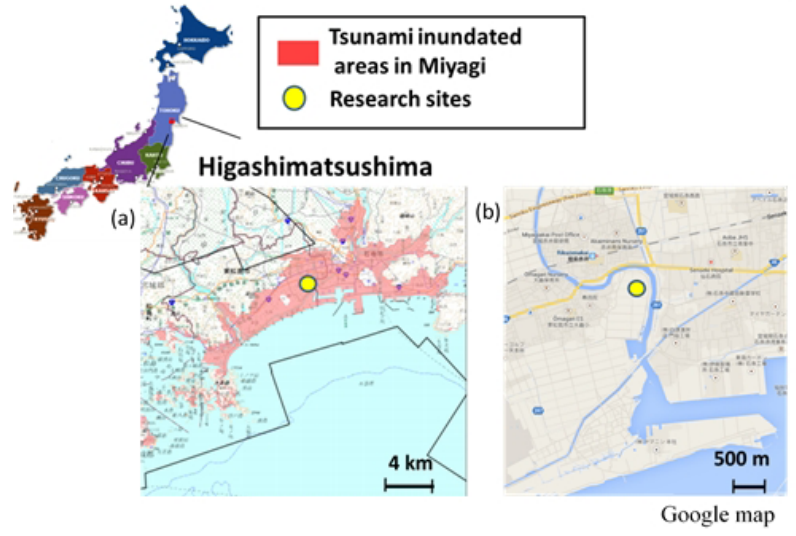

Fig. 1. The map of our research site: Inundated areas of the Tohoku earthquake and massive tsunami in Higashimatsushima, Miyagi (Association of Japanese Geographers, 2011) (a), and the zoom map near our research site (b).

The regions are characterized by a warm humid temperate climate (average monthly temperatures ranged from $1.6^{\circ} \mathrm{C}$ to $24.2^{\circ} \mathrm{C}$ from 1981 to 2010 ), and the average annual 
rainfall is approximately $1100 \mathrm{~mm}$. The rainy season is the best season to reduce soil salinity. Through a previous field survey of the rainy season in July 2013 (Chiba et al., 2014), it was established that $E C_{1: 5}$ was $4 \mathrm{dS} \mathrm{m}^{-1}$ at depths between 10 and $40 \mathrm{~cm}$. In September 2014, $E C_{1: 5}$ dropped below $2.3 \mathrm{dS} \mathrm{m}^{-1}$, but it was still difficult to grow crops such as rice (Oryza sativa L. cv. Hitomebore) and soybeans (Glycin max var. Tanrei) on the farmland. In addition, the long-term high salinity caused cracks near the subsoil surface (Fig. 2).

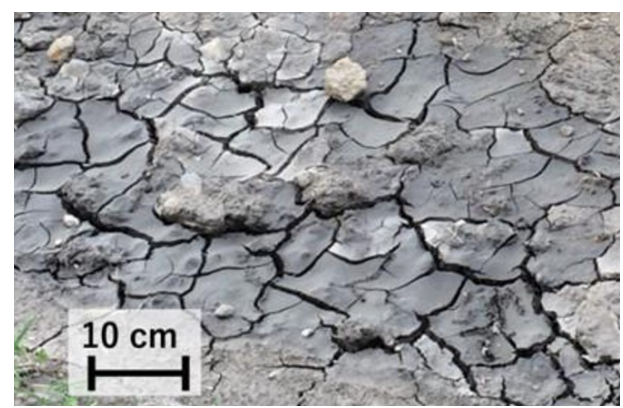

Fig. 2. Picture of cracks on the soil surface before mounting the topsoil layer.

In November 2014, a study was begun in Higashimatsushima to monitor $\theta, E C_{b}$, and soil temperature using FMS with TDT sensors (Acclima) (Fig. 3). Three TDT probes were installed at depths of 15,30 , and $50 \mathrm{~cm}$ under the added soil layer. TDT measurements were recorded every hour in a model CR800 data logger (Campbell Scientific, Logan, UT) and uploaded to the data server at noon through the FR (X-ability). GWL was measured using a CTD sensor (Decagon Devices), hooked up with an Em50 data logger (Decagon Devices). The CTD sensor was placed in a well at a depth of $80 \mathrm{~cm}$ from the soil surface.

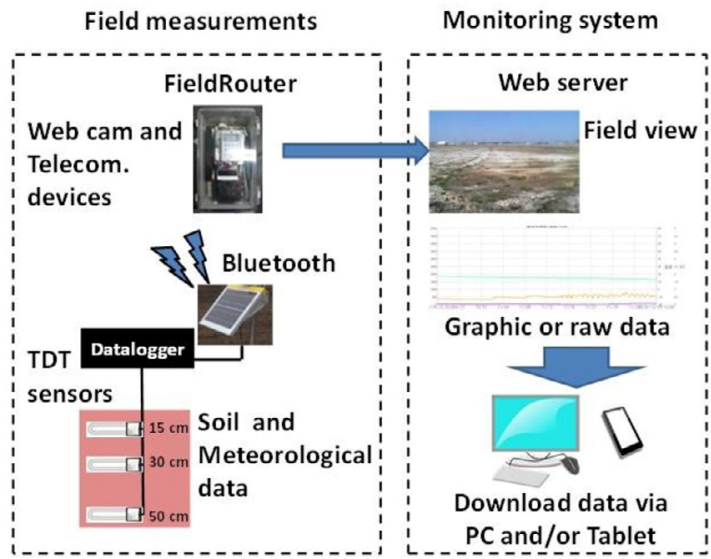

Fig. 3. Diagram of the FMS for remote sensing technique to measure environmental factors $(\theta, E C b$, etc. $)$ at our research site.

Regarding $E C_{b}$, a temperature correction equation was used to obtain $E C_{b}$ values at $25^{\circ} \mathrm{C}\left(E C_{b 25}\right)$ (US Salinity Laboratory Staff, 1954):

$$
E C_{b 25}=E C_{b}\left[1+\frac{298.2-T}{49.7}+\frac{(298.2-T)^{2}}{3728}\right],
$$

where: $T$ is soil temperature (K).
Flood leaching was conducted in a one hectare experimental paddy field from 27 November 2014 to 15 December 2014 under real-time monitoring of $\theta, E C_{b}$, and soil temperature using the FMS. The electrical conductivity of the irrigation water was lower than $0.3 \mathrm{dS} \mathrm{m}^{-1}$, which satisfies the agricultural water quality standard determined by MAFF, Japan (MAFF, 2006). The irrigation water was added, and a water depth of approximately $15 \mathrm{~cm}$ was maintained for 2 weeks. Then, the level of the water table decreased, and the soil was saturated to a depth of $10 \mathrm{~cm}$ until 15 December 2014. The EC of the groundwater was monitored with a CTD sensor in a well at a depth of $80 \mathrm{~cm}$ from the soil surface during the entire leaching period. Photo images confirmed the situation through the use of an FMS webcam.

For the estimation of $E C_{w}$ using Eq. (1), the determination of the empirical parameters, $a$ and $b$, was a requirement. The determination of these empirical parameters was conducted in a walk in temperature controlled laboratory at the standard temperature of $25^{\circ} \mathrm{C}$. To effectively use the limited soil sample in this experiment, $\theta$ and $E C_{b}$ were obtained using TDR measurements. The accuracy of the measurement of $\theta, E C_{b}$, and $E C_{w}$ using TDT was nearly identical to that of TDR because the TDT and TDR methods are based on travel time analysis in the time domain (Uemura et al., 2020). The test was conducted under a range of $E C_{b}$ which was less than $7 \mathrm{dS} \mathrm{m}^{-1}$ in the tsunami-affected soil because of the loss of the TDT transmitted signals. The calibration performed to estimate $E C_{w}$ revealed that the highest $\theta$ and $E C_{b}$ values were $0.56 \mathrm{~m}^{3} \mathrm{~m}^{-3}$ and $6 \mathrm{dS} \mathrm{m}^{-1}$, respectively.

The soil sample originated from the organic rich and muddy sediments in Higashimatsushima, it was taken at a depth between 20 and $40 \mathrm{~cm}$ on 24 September in 2014. The soil was immersed and mixed in water for 1 week, and the $3 \mathrm{~cm}$ depth of flooded water on the soil surface was removed to reduce the soil salinity level. Then, the soil was air dried and sieved with a $2 \mathrm{~mm}$ mesh. After that procedure, the $E C_{1: 5}$ of the washed soil was revealed to be $0.24 \mathrm{dS} \mathrm{m}^{-1}$. An estimation of the empirical constants was performed using a $5 \mathrm{~cm}$ i.d. $\times 20 \mathrm{~cm}$ long cylindrical column. Initially, a known volume of distilled water $\left(E C=1.3 \times 10^{-3} \mathrm{dS} \mathrm{m}^{-1}\right)$ was added using a spray bottle to adjust $\theta$ from 0.15 to $0.5 \mathrm{~m}^{3} \mathrm{~m}^{-3}$. With the use of $\mathrm{NaCl}$ solution $\left(5,10,15,20\right.$, and $\left.30 \mathrm{dS} \mathrm{m}^{-1}\right)$, the soil's $E C_{b}$ was adjusted as well. The sieved soil and $\mathrm{NaCl}$ solution were mixed as uniformly as possible and set aside for 1 week. The column was packed homogeneously with soil with a $\rho_{b}$ of $1.0 \mathrm{~g} \mathrm{~cm}^{-3}$. A CS640 model, 3 rod TDR probe (7.5 cm long, $0.8 \mathrm{~cm}$ rod spacing) (Campbell Scientific, Logan, UT) was installed in the centre of the cylindrical column, and then $\theta$ and $E C_{b}$ were obtained using TDR measurements. A H1400 pF (Kokusan) centrifuge was used to perform the soil solution extraction method, the soil solution was extracted at $6000 \mathrm{rpm}$, and the extracted soil solution $E C$ was measured in terms of $E C_{\mathrm{w}}$ under unsaturated soil conditions. After those measurements were completed, 
$\theta$ and $\rho_{b}$ were then measured using the oven drying method. Through the use of the obtained $\theta-E C_{b}-E C_{w}$ relationship, the empirical parameters of a, $\mathrm{b}$, and $E C_{s}$, were optimized using the non-linear least squares method.

\section{RESULTS AND DISCUSSION}

The measured permittivity $(\varepsilon)-\theta$ relationship was nearly identical to Topp's Eq. (Topp et al., 1980), but Topp's Eq. slightly underestimated $\theta$. For a more accurate estimation of $\theta$, a multiplier of 1.15 was applied, this was obtained by a regression analysis of Topp's Eq., yielding the equation:

$$
\begin{aligned}
& \theta=1.15\left(-5.3 \cdot 10^{-2}+2.9 \cdot 10^{-2} \varepsilon\right. \\
& \left.-5.5 \cdot 10^{-4} \varepsilon^{2}+4.3 \cdot 10^{-6} \varepsilon^{3}\right),
\end{aligned}
$$

with an $\mathrm{r}^{2}$ of 0.98 for a value of $\varepsilon$ which ranged from 3.6 to 31.5 .

The intercept and slope of Eq. (1) for three different water contents $\left(0.275,0.358\right.$, and $\left.0.427 \mathrm{~m}^{3} \mathrm{~m}^{-3}\right)$ and five different $\mathrm{NaCl}$ solutions $\left(5,10,15,20\right.$, and $\left.30 \mathrm{dS} \mathrm{m}{ }^{-1}\right)$ were determined using linear regression analysis. Linear relationships between $E C_{b}$ and $E C_{W}$ were found for all three water contents using salinity levels ranging from 0 to $30 \mathrm{dS} \mathrm{m}^{-1}$, with $\mathrm{r}^{2}$ ranging from $0.97\left(\theta=0.275 \mathrm{~m}^{3} \mathrm{~m}^{-3}\right)$ to $0.99\left(\theta=0.358 \mathrm{~m}^{3} \mathrm{~m}^{-3}\right)$. The estimated values for the intercept $\theta T_{\text {coef }}$ were used to relate $T_{\text {coef }}$ to $\theta$ by using Eq. (2). Best fit parameters, $a, b$ and $E C_{s}$ were $0.96,1 \times 10^{-5}$, and 0.016 respectively $\left(\mathrm{r}^{2}=0.96\right)$. As a result, the $\theta-E C_{b}-E C_{w}$ relationship was non-linear as a function of $\theta$ in the range from 0.1 to $0.5 \mathrm{~m}^{3} \mathrm{~m}^{-3}$ (Fig. 4).

In this relationship, the threshold water content, $\theta_{\mathrm{t}}=-b / a$, which was introduced by Rhoades et al., (1976), was $-1.04 \times 10^{-5} \mathrm{~m}^{3} \mathrm{~m}^{-3}$. Since $\theta_{\mathrm{t}}$ is a negative value, $E C_{w}$ may be determined mathematically from measurements of $E C_{b}$ and $\theta\left(>\theta_{\mathrm{t}}\right)$.

In order to evaluate the estimated $E C_{w}$ value, the estimated $E C_{w}$ was compared with the observed $E C_{w}$ (Fig. 5). The model estimated $E C_{w}$ quite well, and through the exclusion of a few exceptions of $E C_{w}\left(>35 \mathrm{dS} \mathrm{m}^{-1}\right)$, the data coalesced around a 1:1 line $\left(\mathrm{RMSE}=2.84 \mathrm{dS} \mathrm{m}^{-1}\right)$. Thus, the calibration obtained was applied to estimate in situ $E C_{w}\left(\leq 30 \mathrm{dS} \mathrm{m}^{-1}\right)$, even though Rhoades et al., (1976) verified the applicability of Eq. (1) in the range of $\mathrm{EC}_{\mathrm{w}}$ from 2.5 to $56 \mathrm{dS} \mathrm{m}^{-1}$.

From the end of October through to early November 2014, the total rainfall was $20 \mathrm{~mm}$ (Fig. 6a) and $\theta$ fluctuated from 0.3 to $0.56 \mathrm{~m}^{3} \mathrm{~m}^{-3}$ near the soil surface (Fig. 6b). At a depth of $50 \mathrm{~cm}$, however, the soil was almost saturated because of shallow GWL. Using the obtained $\theta-E C_{b}-E C_{w}$ relationship, the estimated in situ $E C_{w}$ at depths of 15, 30, and $50 \mathrm{~cm}$ were $4.13,22.5$, and $10.1 \mathrm{dS} \mathrm{m}^{-1}$ respectively in early November 2014 (Fig. 6c). Before the addition of the topsoil layer, the average GWL was $-9.8 \mathrm{~cm}$ from the soil surface. This shallow GWL suggests that evaporation increased soil salinity in the root zone under the shallow GWL conditions, although the drainage pumping station worked to decrease

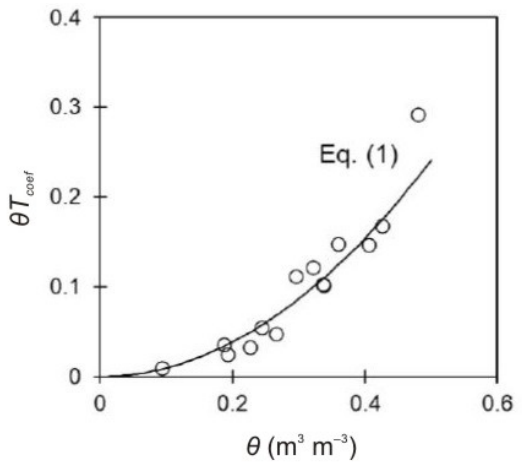

Fig. 4. Relation between the slope pf Eq. (1), $\theta T_{\text {coef }}$ vs volumetric soil water content, $\theta$.

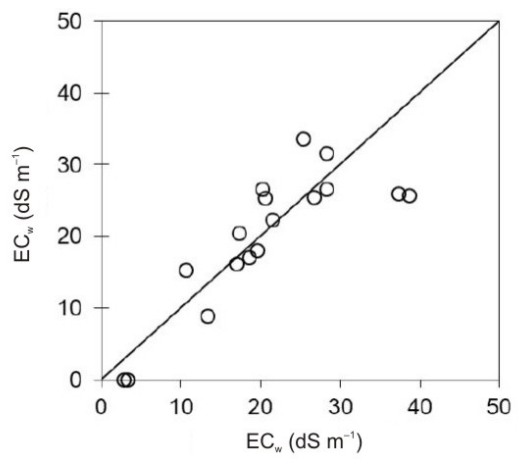

Fig. 5. Comparison of observed $E C_{w}$ with estimated $E C_{w}$ using Rhoades model.

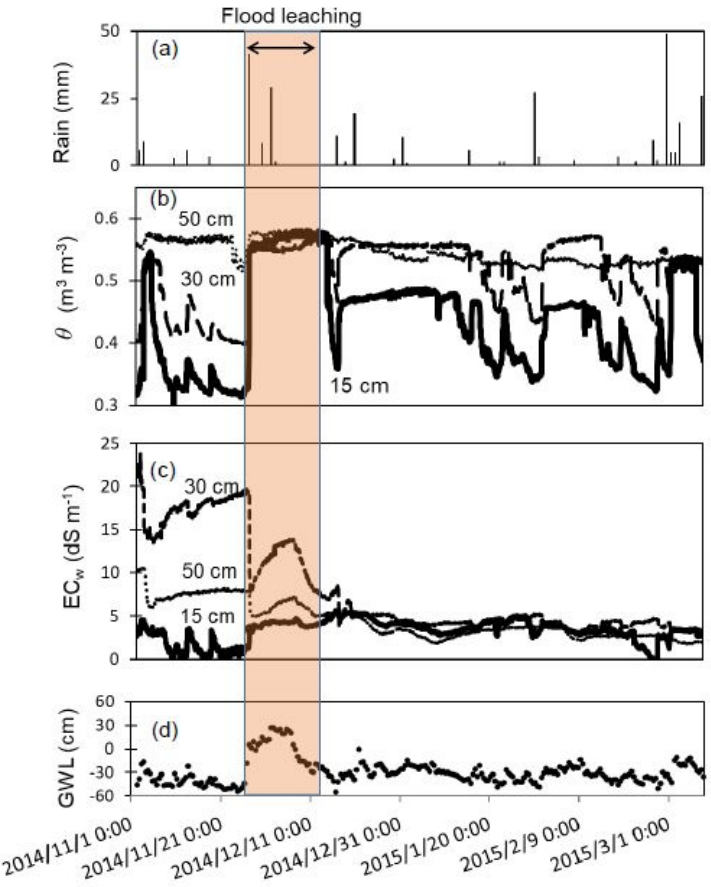

Fig. 6. Temporal changes in rainfall (a), $\theta$ (b), $E C_{w}$ (c), and groundwater level (GWL) (d) at the tsunami affected-agricultural fields in Higashimatsushima.

the GWL. The additional soil reduced the average GWL value (Fig. 6d). Despite this, the research field used required flood leaching to control soil salinity for crop management. 
To facilitate the desalinization process, a flood leaching process was implemented from the end of November through to the middle of December 2014. Figure 7 shows a real time field view of the flooding conditions $(15 \mathrm{~cm}$ flooding water depth) through an FMS webcam. Due to the flooding conditions, $\theta$ reached $0.56 \mathrm{~m}^{3} \mathrm{~m}^{-3}$ to a depth of $50 \mathrm{~cm}$ (Figs $6 \mathrm{~b}$ and $6 \mathrm{~d}$ ), then $E C_{b}$ increased at all of the observed depths (not shown). This trend in $E C_{b}$ is expressed as a function of $\theta$, as shown in Eq. (1), so that $\theta$ variation makes it challenging to understand whether leaching on the desalinization process was successful or not simultaneously.

Before the leaching process was initiated, the $E C$ of the GWL at a depth of $80 \mathrm{~cm}$ was $17.5 \mathrm{dS} \mathrm{m}^{-1}$. At the same time, $E C_{w}$ values were $20 \mathrm{dS} \mathrm{m}^{-1}$ and $10 \mathrm{dS} \mathrm{m}^{-1}$ at depths of $30 \mathrm{~cm}$ and $50 \mathrm{~cm}$, respectively (Fig. 6c). At the beginning of the period when $\theta$ increased up to $\theta_{s}, E C_{w}$ showed a sharp fall at both depths. Then, a pulse shaped $E C_{w}$ was observed except for the $15 \mathrm{~cm}$ depth during the leaching period. The $E C_{\mathrm{w}}$ at a $30 \mathrm{~cm}$ depth reached a maximum in 10 days (December 6th) from the beginning of the leaching period and decreased gradually until it ended. Although MAFF (2011) recommends that flooded leaching treatments should last for a couple of days, FMS's real time investigation made it easier to determine a more effective timing and scheduling of leaching for the tsunami-affected field.

For a quantitative analysis of solute leaching, the total dissolved solute concentration is expressed in the form of the mass of solute per liquid volume (Radcliff and Simunek, 2010). Since dissolved solute concentration has a linear relationship with $\mathrm{EC}_{\mathrm{w}}, \theta, E C_{w}$ may be viewed as an indicator with which to understand the leaching process. Under saturated moisture conditions through flooded leaching or heavy rainfall, the relative concentration of the soil solution was not influenced by $\theta$ in the homogeneous subsoil layer. Figure $8 \mathrm{a}$ shows the time variation of the relative concentration to the maximum concentration during the flooded leaching period. The relative concentration at a depth of $15 \mathrm{~cm}$ was 0.15 and almost constant, but the maximum concentration at a depth of $30 \mathrm{~cm}$ reached 0.5 . It should be noted that at a depth of $80 \mathrm{~cm}$, it increased sharply and peaked after 9 days (December 5th). This indicated that the preferential flow was a robust intrinsic soil property for solute leaching at the boundary between the topsoil and subsoil layers under conditions of saturated moisture.

Solute leaching was also closely monitored during the heavy rainfall period (March 2nd through to March 7th) (Fig. 8b) when the total rainfall was $75 \mathrm{~mm}$. The soil maintained saturated moisture conditions below a depth of $10 \mathrm{~cm}$ (Fig. 6b). The initial relative concentrations were monotonically decreased at all depths, and the relative concentration decreased over time with the exception of the $15 \mathrm{~cm}$ deep soil.

The advantage of $E C_{w}$ is that it can be used to calculate ion concentration in the soil solution if a relationship between $E C_{w}$ and a specific ion concentration is determined.

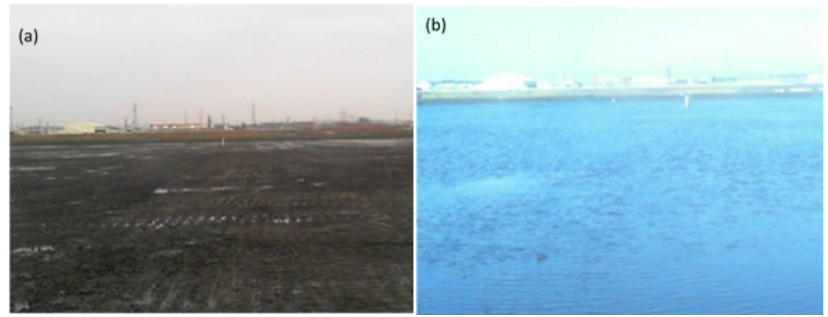

Fig. 7. Field view through the webcam of FMS: before flooded leaching (a), and for the moment of flooded leaching (b) at the tsunami affected-agricultural field.

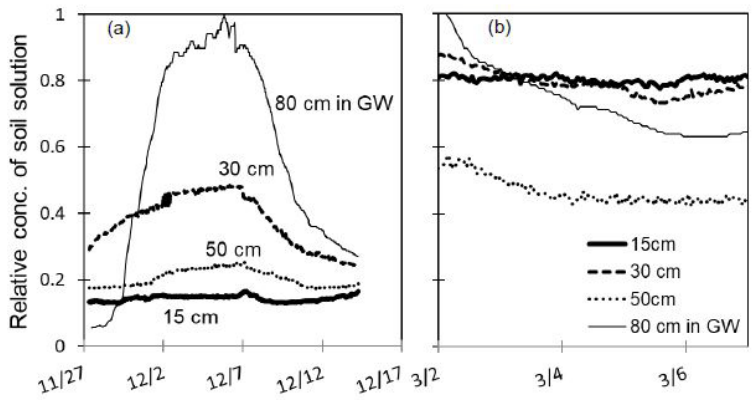

Fig. 8. Relative concentration of soil solution under saturated soil condition during the flooded leaching period (a) and leaching by heavy rainfall period (b).

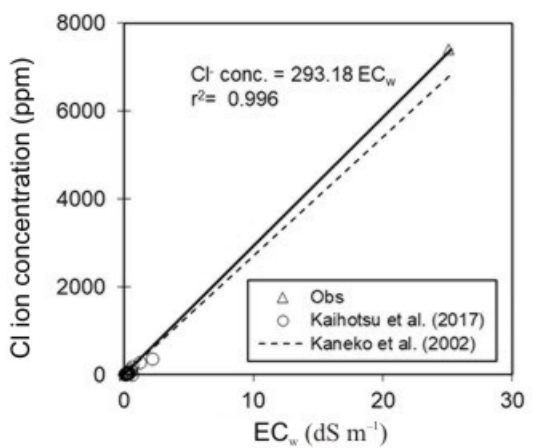

Fig. 9. Relationship between $\mathrm{Cl}$ ion concentration and $E C_{w}$.

Miura (2015) reported that tsunami-affected soil contains a high $\mathrm{NaCl}$ concentration in the soil solution throughout the coastal area surveyed. It is well known that $\mathrm{Cl}^{-}$concentration influences crop yield, and an attempt was made to determine the relationship between $E C_{w}$ and $\mathrm{Cl}^{-}$concentration. Figure 9 shows the estimated relationship, including the data of Kaihotsu et al., (2017) in the range of $\mathrm{Cl}^{-}$concentration $(<400 \mathrm{ppm})$ near the research site. Another calibration of Kaneko et al., (2002) with seawater is also plotted in Fig. 9. These relationships were almost identical in the range of $\mathrm{Cl}^{-}$concentration from 100 to $7400 \mathrm{ppm}$. It is especially noteworthy that a high $\mathrm{Cl}^{-}$concentration influences the crop growth of soybean $(>500 \mathrm{ppm})$ and rice (> 1000 ppm) (Miura, 2015; Abe et al., 2017), this $\mathrm{Cl}^{-}$concentration range corresponded to the observed $E C_{w}$ varying from 3 to $25 \mathrm{dS} \mathrm{m}^{-1}$ by 2015 .

Using the estimated relationship shown in Fig. 9, $E C_{w}$ was converted into $\mathrm{Cl}^{-}$concentration. To evaluate the flooded leaching effect, Fig. 10 shows the profiles of 


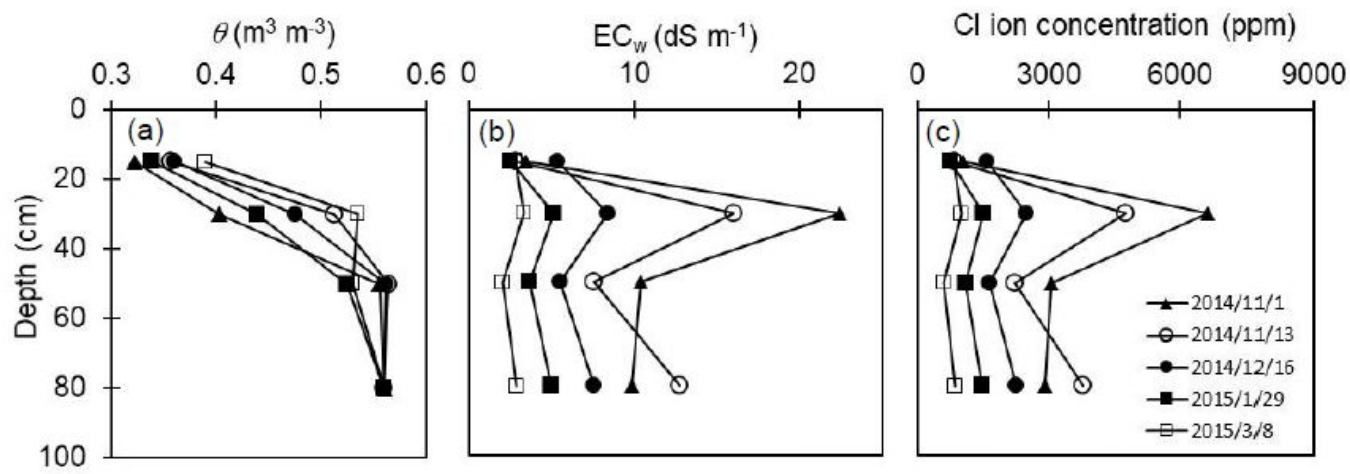

Fig. 10. Profiles of $\theta$ (a), $\theta E C_{w}$ (b), and estimated $\mathrm{Cl}$ ion concentration (c) in the root zone in 2014 through 2015.

$\mathrm{Cl}^{-}$concentration from 2014 to 2015. Changes in the $\theta$ and $E C_{w}$ profiles were plotted in Figs $10 \mathrm{a}$ and $10 \mathrm{~b}$ and compared with the profiles of $\mathrm{Cl}^{-}$concentration. After the flood leaching process, $\theta$ was maintained in an unsaturated moisture condition, this varied from 0.3 to $0.5 \mathrm{~m}^{3} \mathrm{~m}^{-3}$ in the root zone (Fig. 10a). It was found that the flood leaching process in combination with the addition of a topsoil layer decreased $\mathrm{Cl}^{-}$concentration from 6600 to $2500 \mathrm{ppm}$ in the root zone, then it dropped to approximately $1,000 \mathrm{ppm}$ by March 2015 as a result of natural rainfall events (Fig. 10c). This result suggests that the added topsoil treatment and two weeks of flooded leaching were very effective in reducing the soil salinity level because natural rainfall could not decrease it for three and a half years after the earthquake. Nevertheless, it was found that flooded leaching alone did not allow for a decrease in $\mathrm{Cl}^{-}$concentration to the proper soil salinity level required for rice growth.

Some studies have reported the natural recovery of tsunami-affected paddy soils due to rain, and Terasaki et al., (2015) found a relationship between the variation of salt mass content over time and rainfall depth in other regions of Miyagi. However, the research site in Higashimatsushima indicated an exception to the desalinization process. One uncertain possibility is that the subsidence effect might result in lower soil permeability under shallow GWL conditions. Contrary to this inference, the three year high soil salinity resulted in crack formation (Fig. 2), thereby indicating preferential flows near the soil surface. During the added topsoil treatment, soil compaction, which occurred due to the passage of machinery, may have increased water flow through cracks under flooding conditions. These different water flow domains would change the solute exchange time at the boundary between the topsoil and subsoil layers, however, much salt was flushed well below the $30 \mathrm{~cm}$ depth through the drainage pumping station.

An adverse effect of preferential flow on salt leaching through cracks is the increase in the leaching requirement (LR), the fraction of infiltrated water that must pass through the root zone to prevent soil salinity from exceeding a level that would significantly reduce crop yield. For example, assuming that the water flowing through cracks does not dissolve salts in micropores, Fujimaki et al., (2021) calculated that nearly twice as much water might be required for the LR through their experiments. In addition, the $\mathrm{Cl}^{-}$ (solute exchange) transport time is longer than the water flow time because of $\mathrm{Cl}^{-}$diffusive transport (Toride et al., 2003; Tokumoto et al., 2005; Tokumoto et al., 2007). In this study, downward water flow was confirmed because of the pulse shaped $E C_{w}$, thereby indicating that solute moved deeper under flooding conditions (Fig. 8a). An $E C_{w}$ value of 30 at a depth of $50 \mathrm{~cm}$ was maintained for a maximum of 10 days from the beginning of the leaching process (Fig. 8a), although MAFF (2011) only recommends a couple of days for flooded leaching treatment. This extended leaching period would be affected by preferential flow in soil cracks between the topsoil and subsoil layers.

After the flooded leaching process was terminated, preferential flow could no longer remain dominant in unsaturated conditions, and solute transport became horizontally uniform during natural rain events. By March 2015, during $140 \mathrm{~mm}$ rainfall, $\mathrm{Cl}^{-}$concentration almost reached $1000 \mathrm{ppm}$, which was appropriate for rice growth. $140 \mathrm{~mm}$ rainfall, which corresponded to the cumulative surface water from flooded leaching, contributed soil salinity control to rice growth management, but it was insufficient for the soybean cropping system. Indeed, the rice grew well in 2015 , however, soybean growth was affected by the remaining salt. Even if an appropriate $\theta$ level was maintained with a tile drainage system (not shown), soybean growth may have been influenced by the remaining salt concentration, this is supported by the research of Abe et al., (2017).

\section{CONCLUSIONS}

1. At the tsunami-affected agricultural fields in Higashimatsushima, where severe subsidence occurred, Field Monitoring System may be performed adequately enough to measure a high bulk soil electrical conductivity value $\left(<6 \mathrm{dS} \mathrm{m}^{-1}\right)$ even at high volumetric soil water content $\left(<0.56 \mathrm{~m}^{3} \mathrm{~m}^{-3}\right)$ using time domain transmission sensors. Pore water electrical conductivity $\left(\leq 30 \mathrm{dS} \mathrm{m}^{-1}\right)$ may be determined using bulk soil electrical conductivity and volumetric soil water content obtained from the Rhoades model. 
2. After two weeks of applying the flooded leaching method and spreading a $10 \mathrm{~cm}$ topsoil layer, a decline in pore water electrical conductivity was found in the root zone due to leaching below a depth of $30 \mathrm{~cm}$. However, this was insufficient to manage crop growth near the subsoil layer, where preferential flows were predominant.

3. Pore water electrical conductivity was a beneficial indicator concerning the threshold of $\mathrm{Cl}^{-}$concentration required to determine a soil salinity level that would significantly reduce rice and soybean yield. Consequently, the utilization of Field Monitoring System is expected to provide a positive feedback for the recovery of agricultural production.

Conflict of interest: The authors do not declare any conflict of interest.

\section{ACKNOWLEDGEMENTS}

We thank Dr. Nobuo Toride and Dr. Masaru Sakai, Mie University, for their constructive comments regarding water and solute transport.

\section{REFERENCES}

Abe T., Sato K., and Hasebe K., 2017. Effects of seawater salinity on the soybean (in Japanese). Bull. Miyagi Pref. Furukawa Agric. Exp. Stn., 12, 57-66.

Association of Japanese Geographers, 2011. Map of tsunami inundation reported by Tsunami Damage Team2011, available at: http://danso.env.nagoya-u.ac.jp/20110311/map/index_e.html

Blonquist Jr. J., Jones S., and Robinson D., 2005. A time domain transmission sensor with TDR performance characteristics. J. Hydrol., 314, 235-245, https://doi.org/10.1016/j. jhydrol.2005.04.005

Chiba K., Goko M., Kanmuri H., Kato K., and Kato T., 2014. Effective of desalinization by infiltration of water and monitoring of groundwater on tsunami-hit farmland (in Japanese). Water Sci., 58, 121-142.

Chiba K., Kanmuri H., and Kato T., 2015. Recovery of farmlands from the tsunami damage using the agricultural engineering technology (in Japanese). J. Japanese Soc. Soil Physics, 129, 13-18.

Earthquake and reconstruction division of miyagi prefecture, 2014. Situation of recovery of agricultural fields in Miyagi Prefecture (in Japanese). http://www.pref.miyagi.jp/site/ejearthquake/list441-510.html

Fujimaki H., and Abd EI Baki H.M., 2021. Effect of bypassflow on leaching of salts in a cracking soil in the Nile Delta. Water, 13, https://doi.org/10.3390/w13070993

Hirashima Y., Miyamoto H., and Yuge K., 2020. Soil moisture and salinity monitoring in reclaimed agricultural fields using Time Domain Transmissiometry (TDT) sensors (in Japanese with English Summary). Trans. JSIDRE, 310, 21-28.

JIID (The Japanese Institute of Irrigation and Drainage), 2013. Workshop report on the salt removal technology in agricultural lands, March, 2013. URL: http://www.jiid.or.jp/news/ 20130328.pdf

Jury W.A. and Horton R., 2004. Soil physics $6^{\text {th }}$ Edition. John Wiley and Sons, Inc., New York.
Kaihotsu I., Onodera S., Shimada J., and Nakagawa K., 2017. Recovery of groundwater in the Sanriku region contaminated by the tsunami inundation from the 2011 Tohoku earthquake. Environ. Earth Sci., 76, https://doi.org/10.1007/ s12665-017-6569-x

Kaneko T., Murakawa M., Kozai N., and Mitsugi K., 2002. Desalting technique for illuviated salts soil at paddy field by using underdrainage (in Japanese). J. Agri. Eng. Soc. Japan, 70(7), 611-614.

MAFF (Ministry of Agriculture, Forestry and Fisheries), 2006. Agriculture water quality standard, url: http://www.naro. affrc.go.jp/archive/niaes/techdoc/monitoring/

MAFF (Ministry of Agriculture, Forestry and Fisheries), 2011. Manual for salinity reclamation in agricultural land, Rural Development Bureau, June, 2011, URL: http://www.maff. go.jp/j/press/nousin/sekkei/pdf/110624-01.pdf

Malicki M.A. and Walczak R.T., 1999. Evaluating soil salinity status from bulk electrical conductivity and permittivity. European J. Soil Sci., 50, 505-514, https://doi.org/10.1046/ j.1365-2389.1999.00245.x

Mallants D., Vanclooster M., Toride N., Vanderbrorght J., van Genuchten M.Th. and Feyen J., 1996. Comparison of three methods to calibrate TDR for monitoring solute movement in unsaturated soil. Soil Sci. Soc. Am. J., 60, 747-754, https://doi.org/10.2136/sssaj1996.03615995006000030010x

Miura K., 2015. Measures of desalinization in tsunami-hit farmland. 16. Measures of soil desalinization in tsunami affected farmland in the Tohoku district. J. Sci. Soil Manure, 86(5), 459-462.

Miyamoto T., Kameyama K., and Iwata Y., 2015. Monitoring electrical conductivity and nitrate concentrations in an Andisol field using time domain reflectometry. Japan Agric. Res. Quarterly, 49(3), 261-267, https://doi.org/10.6090/jarq.49.261

Miyamoto H., Ito N., Mase A., Tokumoto I., and Chikushi J., 2013. Application of time domain transmissiometry to coupled measurements of soil moisture and electrical conductivity (in Japanese with English Summary). Trans. JSIDRE, 288, 25-31.

Mizoguchi M., Ito T., and Kobayashi D., 2012. Environmental monitoring of village contaminated by radionuclides. Proceedings of AFITA/WCCA 2012, http://www.iai.ga.a.utokyo.ac.jp/mizo/edrp/fukushima/fsoil/Seminar\%20 (19)-03.pdf

Mualem Y., 1976. A new model for predicting the hydraulic conductivity of unsaturated porous media. Water Resour. Res., 12, 513-522, https://doi.org/10.1029/WR012i003p00513

Muñoz-Carpena R., Regalado C.M., Ritter A., Alvarez-Benedi J., and Socorro A.R., 2005. TDR estimation of electrical conductivity and saline solute concentration in a volcanic soil. Geoderma, 124, 399-413, https://doi.org/10. 1016/j. geoderma.2004.06.002

Noborio K., 2001. Measurement of soil water content and electrical conductivity by time domain reflectometry: a review. Computers Electronics in Agri., 36, 113-132.

Radcliffe D.E. and Šimůnek, J., 2010. Soil Physics with Hydrus. CRC Press, Boca Raton, London and New York.

Risler P.D., Wraith J.M., and Gaber H.M., 1996. Solute transport under transient flow conditions estimated using time domain reflectometry. Soil Sci. Soc. Am. J., 60, 1297-1305, https://doi.org/10.2136/sssaj1996.03615995006000050003x 
Rhoades J.D., Manteghi N.A., Shouse P.J., and Alves W.J., 1989. Soil electrical conductivity and soil salinity: New formulations and calibrations. Soil Sci. Soc. Am. J., 53, 433-439, https://doi.org/10.2136/sssaj1989.03615995005300020020x

Rhoades J.D., Raats P.A., and Prather R.J., 1976. Effects of liquid-phase electrical conductivity, water content, and surface conductivity on bulk soil electrical conductivity. Soil Sci. Soc. Am. J., 40, 651-655, https://doi.org/10.2136/sssaj1976. $03615995004000050017 \mathrm{x}$

Roy K., Kato Y., Sato N., and Nagasaki N., 2015. Post-tsunami salinity status of reclaimed and nonreclaimed farmlands in Miyagi Prefecture, Japan. J. Environ. Information Sci., 43, 19-24.

SDI-12 support group, 2012. SDI-12 a serial-digital interface standard for microprocessor-based sensors version 1.3.

Seki K., Miyamoto T., and Iwata Y., 2019. Estimation of electrical conductivity of a soil solution from the monitored TDR data and an extracted soil solution. Int. Agrophys., 33, 113119, https://doi.org/10.31545/intagr/104413

Terasaki H., QIU Q., Takezaki H., and Fukuhara T., 2015. Natural recovery of salt affected paddy field due to rainfall. J. Japan Soc. Civil Eng., 71, 1663-1668, https://doi.org/ 10.2208/kaigan.71.I_1663
Tokumoto I., Toride N., and Inoue M., 2005. Hydrodynamic dispersion for an Andisol with aggregated soil structure (in Japanese). J. Japan Soc. Hydrol. and Water Resour. Res., 18, 401-410, https://doi.org/10.3178/jjshwr. 18.401

Tokumoto I., Toride N., and Inoue M., 2007. Water flow and solute transport in undisturbed Andisols (in Japanese). Trans. JSIDRE, 252, 51-60.

Topp G., Davis J., and Annan A., 1980. Electromagnetic determination of soil-water content- measurements in coaxial transmission-lines, Water Resour. Res., 16, 574-582, https://doi.org/10.1029/WR016i003p00574

Toride N., Inoue M., and Leji F.J., 2003. Hydrodynamic dispersion in an unsaturated dune sand. Soil Sci. Soc. Am. J., 67, 703-712, https://doi.org/10.2136/sssaj2003.0703

Uemura M., Miyamoto H., and Noborio K., 2020. Comparison of the performance of TDR and TDT for the evaluation of soil moisture and electrical conductivity of Toyoura sand (in Japanese). Trans. JSIDRE, 310, 117-124.

US Salinity Laboratory Staff. 1954. Diagnosis and improvement of saline and alkali soils. USDA Agric. Handb., 60. 